Pressure studies of impurity levels in $\mathrm{Al}_{x} \mathrm{Ga}_{1-\mathrm{x}} \mathrm{As}$

This article has been downloaded from IOPscience. Please scroll down to see the full text article.

1989 Semicond. Sci. Technol. 4290

(http://iopscience.iop.org/0268-1242/4/4/033)

View the table of contents for this issue, or go to the journal homepage for more

Download details:

IP Address: 128.206.162.204

The article was downloaded on 05/08/2010 at 19:05

Please note that terms and conditions apply. 


\title{
Pressure studies of impurity levels in $\mathrm{Al}_{x} \mathrm{Ga}_{1-x}$ Ast
}

\section{W P Roach $¥$, M Chandrasekhar $\neq$, H R Chandrasekhar $\neq$, F A Chambers $\S$ and J M Meese $\S$}

₹ Department of Physics, University of Missouri, Columbia, MO 65211, USA

$\S$ Amoco Research Center, Naperville, IL 60566, USA

Received 30 September 1988, accepted for publication 8 December 1988

\begin{abstract}
We present a study of the deep and shallow donor levels under hydrostatic pressure. The shallow levels follow the conduction bands, while the deep levels are strongly sublinear with pressure. The temperature dependence of the intensities and energies is used to obtain an energy level diagram of the deep levels at high pressures.
\end{abstract}

\section{Introduction}

It is well known that the application of hydrostatic pressure moves the conduction bands (СB) in GaAs in a manner similar to alloying with AlAs: the initial $\Gamma-\mathrm{L}-\mathrm{X}$ ordering changes to $\mathrm{X}-\mathrm{L}-\Gamma$ both with higher $\mathrm{Al}$ composition and with hydrostatic pressure. We present a study of $\mathrm{Al}_{x} \mathrm{Ga}_{1-x} \mathrm{As}$ (with $\sim 10^{15} \mathrm{~cm}^{-3} \mathrm{Si}$ ) up to a pressure of $60 \mathrm{kbar}$ at temperatures between 15 and $125 \mathrm{~K}$ using photoluminescence ( $\mathrm{PL}$ ) spectroscopy. Shallow donor levels that manifest themselves both via bound exciton (BE) and donor-acceptor (DA) recombination are observed at low pressures, where the lowest $C B$ is still at $\Gamma$. BE and deep-donor-to-acceptor recombination are seen at higher pressures where the lowest at $X$. At a few pressures chosen to be typical of $\Gamma$ and $X$, we study the temperature evolution of the PL spectrum and its dependence on excitation intensity. We obtain activation energies and thereby an energy level scheme for the sample as the lower $\mathrm{CB}$ changes from $\Gamma$ to $\mathrm{X}$.

\section{Results and discussion}

Our experiments were carried out on MBE-grown samples $1 \mu \mathrm{m}$ thick on a GaAs substrate. The samples were undoped but contain some silicon impurities [2]. A diamond anvil cell was used with $\mathrm{Ar}$ as the pressure transmitting medium, and the $5145 \AA$ laser line was used to excite the PL.

Figure 1 is a plot of the peak energies of various transitions observed under pressure. Data from two samples with $x=0.29[1]$ and $x=0.30$ are included in

† Based on a paper presented at The High Pressure in

Semiconductor Physics conference organised by the High Pressure Research Centre of the Polish Academy of Sciences, Warsaw on 20-21 August 1988. this plot. The energy axes are shifted so that the BE at zero pressure coincide. At 1 bar, a strong $B E(\Gamma)$ and a weaker DA peak are seen. The BE $(\Gamma)$ shifts at the rate

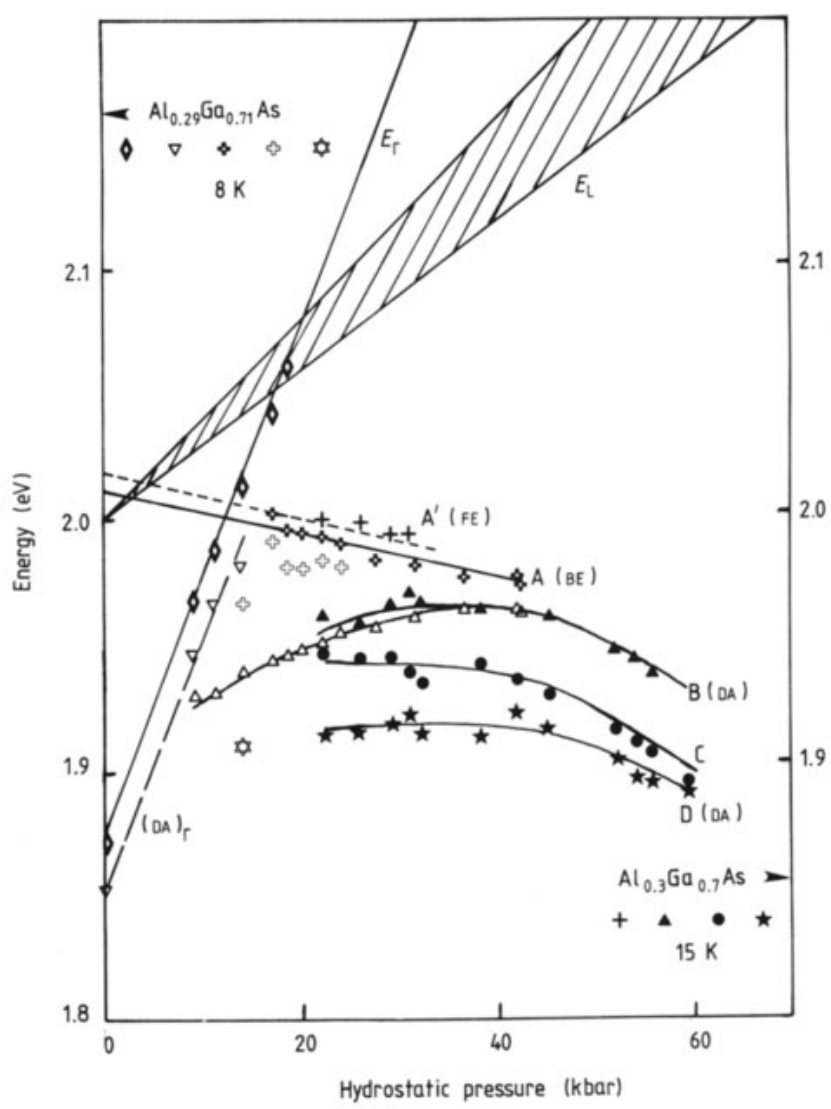

Figure 1. Energies of the peaks in the PL spectra of $\mathrm{Al}_{0.29} \mathrm{Ga}_{0.71} \mathrm{As}$ and $\mathrm{Al}_{0.3} \mathrm{Ga}_{0.7} \mathrm{As}$ as a function of pressure. The data from both samples have been plotted so that the $\mathrm{BE}(\Gamma)$ peaks coincide at zero pressure. Note the appearance of transitions from deep donor levels beyond 9 kbar. 
of $9.9 \pm 0.1 \mathrm{meV} \mathrm{kbar}^{-1}$. Around $9 \mathrm{kbar}$, new peaks from the deep-donor levels are observed. The strongest, labelled B, has a non-linear pressure behaviour: it increases in energy between 9 and $30 \mathrm{kbar}$, flattens and then decreases in energy after $40 \mathrm{kbar}$. This is typical of deep donor levels that do not follow any particular band. A weak shoulder, C, and second deeper level, D, are also observed to have a similar pressure dependence.

In order to determine whether the peak $\mathrm{D}$ is a separate donor level or a phonon replica of $B$, we studied the PL intensity as a function of exciting laser intensity. We found that peak D scales with B up to an intensity of $1 \mathrm{~W} \mathrm{~cm}^{-2}$, beyond which it saturates and only then other recombination mechanisms such as peak $B$ and the BE (X) (peak A) and $F E(X)$ (peak $A^{\prime}$ ) become viable [2]. We therefore conclude that $\mathrm{D}$ may arise from a different donor level which is deeper than B.

The excitons associated with the $\mathrm{X} \mathrm{CB}$, labelled $\mathrm{A}$ (BE) and $\mathrm{A}^{\prime}$ (FE) are observed beyond $14 \mathrm{kbar}$, and shift at the rate of about $-1 \mathrm{meV} \mathrm{kbar}^{-1}$. It should be noted that at high pressure ( $>40 \mathrm{kbar}$ ), peak $\mathrm{B}$ is the most intense, and it shifts in that region at the rate of about $-2 \mathrm{meV} / \mathrm{kbar}^{-1}$. Care should be taken not to identify it as the exciton, especially in situations where staggered transitions in GaAs-AlGaAs quantlum-well systems are used to determine the valence band offsets $[3,4]$.

The temperature dependence of the energies and intensities of the PL spectra were used to determine activation energies and scattering mechanisms at a few chosen pressures that are typical of the $\Gamma$ and the X CBs. The $\Gamma$ СB region is well described by the zero pressure spectrum. PL spectra in the $\mathrm{X}$ CB region, at $26 \mathrm{kbar}$, are shown at several temperatures in figure 2 . The individual energy axes for the spectra have been shifted (relative to the lowest axis) to compensate for the change in the $\mathrm{X}$ band gap with temperature [5] (GaAs values were used for the Varshni coefficients). All spectra were taken with an exciting intensity of $40 \mathrm{~W} \mathrm{~cm}^{-2}$. At $15 \mathrm{~K}$, the BE (peak A), and two DA recombination peaks (B and D) are seen. It is evident from figure 2 that the peaks change both in intensity and energy.

In figure 3 we plot the peak energy positions (circles) as a function of temperature. The triangles are the peak energy positions shifted by the change in the $\mathrm{X}$ band gap with temperature. We see that as the temperature is raised, the BE shifts to higher energies by about $25 \mathrm{meV}$ between 15 and $125 \mathrm{~K}$, suggesting an ionisation of the level. In the zero-pressure case a similar plot showed the $\mathrm{BE}(\Gamma)$ increasing to the energy of the FE. Here the energy increases smoothly with temperature. This smearing is reasonable since it requires a phonon in order to make the transition, and both phonon emission and absorption are possible at higher temperatures, as well as several different phonon processes.

The DA peaks B and D shift down slightly in energy up to about $75 \mathrm{~K}$, beyond which they decrease in

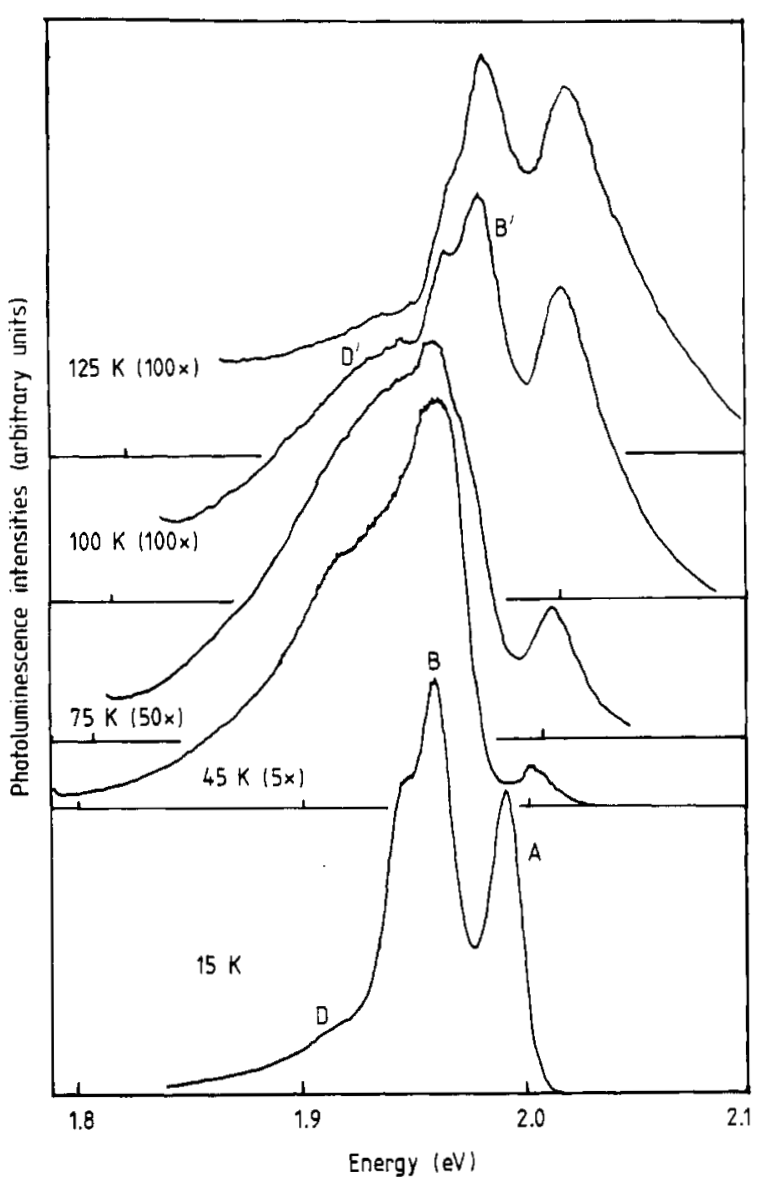

Figure 2. PL spectra for $\mathrm{Al}_{0.3} \mathrm{Ga}_{0.7} \mathrm{As}$ at $26 \mathrm{kbar}$ for several temperatures. The lowest energy axis corresponds to energies at $T=0$, and the other axes are shifted by an energy equal to the temperature shift of the $X$ band gap.

intensity and new peaks appear at higher energies ( $B^{\prime}$ and $\mathrm{D}^{\prime}$ in figures 2 and 3 ). At $125 \mathrm{~K}, \mathrm{~B}^{\prime}$ is strong and $\mathrm{D}$ disappears entirely. Peaks $\mathrm{B}^{\prime}$ and $\mathrm{D}^{\prime}$ are about $20 \pm 5 \mathrm{meV}$ above the $15 \mathrm{~K}$ levels of $\mathrm{B}$ and $\mathrm{D}$, after

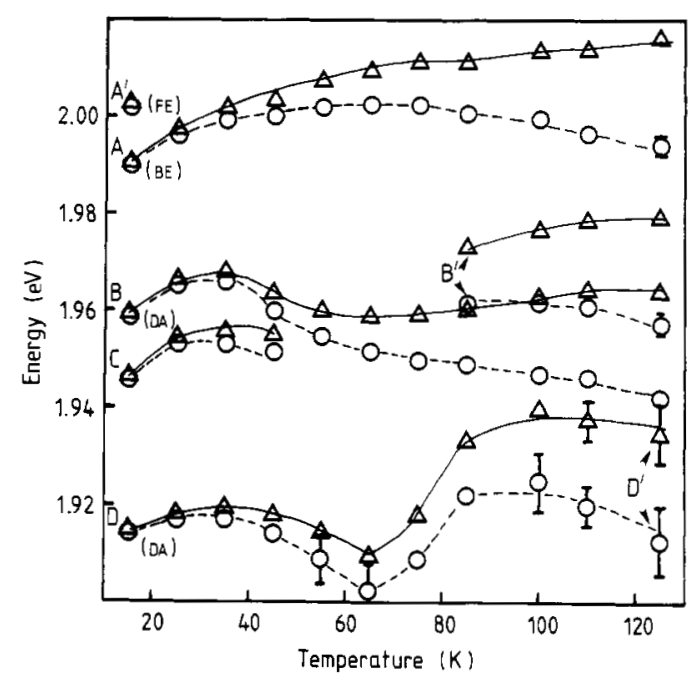

Figure 3. Peak energies of PL spectra of $A \mathrm{I}_{0.3} \mathrm{Ga}_{0.7} \mathrm{As}$ at $26 \mathrm{kbar}$ as a function of temperature. The circles correspond to actual peak energies, and the triangles are the energy positions corrected for the temperature shift of the $X$ band gap. 
Table 1. Activation energies at zero and $26 \mathrm{kbar}$.

\begin{tabular}{|c|c|c|c|c|}
\hline Pressure & Transition & $\begin{array}{l}E_{\mathrm{a}} \\
(\mathrm{meV})\end{array}$ & $\begin{array}{l}\text { Temperature } \\
\text { range }(\mathrm{K})\end{array}$ & Mechanism \\
\hline \multirow[t]{3}{*}{ Zero } & $\mathrm{FE}$ & $12 \pm 2$ & 35 to 75 & To $\Gamma \mathrm{CB}$ \\
\hline & FE & $80 \pm 10$ & 75 to 125 & Higher L CB \\
\hline & DA & $22 \pm 3$ & 35 to 85 & $\begin{array}{l}\text { Ionisation of } \\
\text { acceptor }\end{array}$ \\
\hline \multirow[t]{3}{*}{$26 \mathrm{kbar}$} & $\mathrm{BE}(\mathrm{A})$ & $7 \pm 1$ & 15 to 55 & $\mathrm{BE}$ to $\mathrm{FE}$ \\
\hline & $F E\left(A^{\prime}\right)$ & $38 \pm 4$ & 55 to 125 & To $X$ CB \\
\hline & $\mathrm{DA}(\mathrm{B})$ & $52 \pm 5$ & 65 to 125 & To $X C^{\prime}$ \\
\hline
\end{tabular}

correcting for the temperature shift. This suggests an ionisation of the acceptor level.

The intensities of the peaks as a function of temperature were analysed via Arrhenius plots [4]. The linear parts of the curves give the activation energies shown in table 1.

From the activation energies $E_{\mathrm{a}}$ and peak energies as a function of temperature we draw an energy level diagram (figure 4). The energies for the $\Gamma$ св (at zero pressure) are in good agreement with the data of Dingle [6]. At high pressure, peaks B and D probably arise from DA recombination from different donor levels, since they have different excitation intensity dependences. They terminate on the same acceptor level, since the ionisation energy for both peaks is the same and occurs at the same temperature, (figure 3). The acceptor, from its ionisation energy and from zero pressure DA energy, is believed to be $\mathrm{C}_{\mathrm{AS}}$ [7]. The peak $\mathrm{B}$ is about $55 \mathrm{meV}$ below the $\mathrm{X} \mathrm{CB}$ (assuming the $\mathrm{BE}$ is $45 \mathrm{meV}$ below $\mathrm{X}$ ) and $\mathrm{D}$ is $\sim 100 \mathrm{meV}$ below $\mathrm{X}$. The position of peak $D$ agrees with the $D^{L}-A$ transition seen by Henning [8], since it is 180 to $200 \mathrm{meV}$ below the $\mathrm{L}$ СB (figure 1 ).

At this time the origin of these levels is not definitely known, though it is reasonably certain that they arise from Si donors. Further detailed temperature and excitation intensity studies over the entire pressure range are in progress.

\section{Acknowledgments}

This work was supported by the US Army under grant number DAAL03-86-K-0083, the US Department of Energy under grant number DE-AC02 84ER45048,

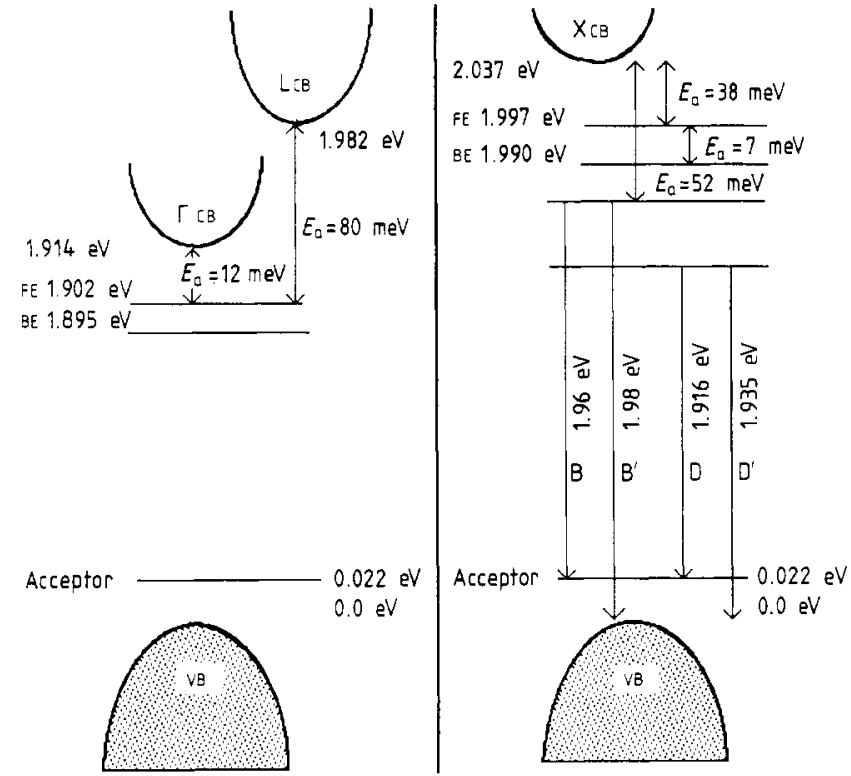

Figure 4. Energy level diagram of the levels observed for zero (left-hand side) and $26 \mathrm{kbar}$ (right-hand side). The energy separations are deduced from activation energies and shifts in the energies of the peaks as a function of temperature (figure 3 ).

and Amoco Corporation. $\mathrm{M}$ Chandrasekhar is an AP Sloan Foundation Fellow.

\section{References}

[1] Chandrasekhar M, Venkateswaran U, Chandrasekhar H R, Vojak B A, Chambers F A and Meese J M 1987 Proc. 18th Int. Conf. Physics of Semiconductors ed. O Engstrom (Singapore: World Scientific) p943

[2] Roach W P, Chandrasekhar M, Chandrasekhar H R, Chambers F A and Meese J M 1989 Proc. 19th Int. Conf. Physics of Semiconductors (Warsaw) 1988

[3] Venkateswaran U, Chandrasekhar M, Chandrasekhar $\mathrm{H}$ R, Vojak B A, Chambers F A and Meese J M 1986 Phys. Rev. B33 8416

[4] Wolford D J, Kuech T F, Bradley J A, Gell M G, Ninno D and Jaros M $1986 \mathrm{~J}$. Vac. Sci. Technol. B4 1043

[5] Aspnes D E 1976 Phys. Rev. B14 5331

[6] Dingle R 1977 Gallium Arsenide and Related Compounds (Edinburgh) 1976 (Inst. Phys. Conf. Ser. 33a) p 210

[7] Swaminathan V, Zilko J L, Tsang W T, and Wagner W R 1982 J. Appl. Phys. 535163

[8] Henning J C M and Ansems J P M 1987 Semicond. Sci. Technol. 21 and references therein 